\title{
BLINDED BY GOLD: TORONTO SPORTS COMMUNITY IGNORES NEGATIVE LEGACIES OF 2015 PAN AM GAMES
}

\author{
MADELEINE ORR* AND NIGEL JARVIS $†$ \\ *School of Kinesiology, University of Minnesota, Minneapolis, MN, USA \\ †School of Sport and Service Management, University of Brighton, Eastbourne, UK
}

\begin{abstract}
Event organizers and city officials often justify the high costs of hosting an event by highlighting its legacies. Legacies are a topic of contentious discourse among event researchers, over definition, measurement, and significance. The bid for the Toronto 2015 Pan Am Games highlighted sport legacies as a priority. Thirteen semistructured qualitative interviews were conducted with organizers, city officials, and members of the Toronto sports community. These interviews were analyzed using a thematic coding method. The degree of familiarity with "event legacies" among respondents varied, as did the definitions they offered. Multiple positive legacies were highlighted, most frequently: new or improved sports facilities and equipment (11/13 respondents), increased awareness of sport and sport opportunities (9/13), and inspiration factor (7/13). No respondent named negative legacies. Two major themes emerged: 1) there is no universal understanding of legacies as a term or concept; and 2) organizers are biased when asked about legacies, favoring the positive, and ignoring the negative.
\end{abstract}

Key words: Legacy; Sport event; Sport participation; Stakeholders; Interview

Introduction

Organizers of international sporting events often justify the efforts and high costs associated with the event by highlighting its expected legacies (Thomson, Schlenker, \& Schulenkorf, 2013). However, there is insufficient empirical evidence to show that this justification is founded (Cashman, 2006; Gold \& Gold, 2009). The Toronto 2015 Pan Am Games were the first international multisport event the city has hosted, following on the heels of five unsuccessful Olympic bids (Oliver, 2013), and Toronto’s first multisport event in 2012; the Ontario Summer Games. The city's leaders appear to be subscribers to the belief that mega-events have the potential to serve as an economic growth industry (Hall, 1992; Oliver, 2013) and to generate positive outcomes for the city economically, socially, and politically (Curi, Knijnik, \& Mascarenhas, 2011; Preuss, 2007). And although the bids until now have been unsuccessful, 
one researcher points out that "each bid creates the potential to have a conversation about the status and vision of the bid city . . . even if the city ultimately fails to win hosting rights” (Oliver, 2013, p. 204). Each new proposal has allowed the city's leaders to review their legacy objectives, and to develop event-led and event-based strategies for city rejuvenation in the development of positive legacies. This led to the bid for Pan Am, which highlighted sport legacies as a priority. The argument presented in the document was:

Hosting the Pan American Games in Toronto will benefit sport at all levels. Across the Toronto region, new facilities will be built, and existing ones improved. There will be an opportunity for greater sport participation at the community level as well as new opportunities for high-performance sport development at the provincial, national and international levels. (TO2015 Bid Committee, 2009, p. 199)

It will take extensive research and many years of review to determine whether these expected legacies will be realized.

The Pan American Games are a regional multisport event governed by the Pan American Sport Organization (PASO). The first games were held in Buenos Aires in 1951 with more than 2,500 athletes and 22 countries represented. Since then, the Pan Am Games have been held three times in Canada, twice in Winnipeg (1967 and 1999), and once in Toronto in 2015. For many sports, the Pan Am Games and the Parapan Am Games that accompany them are a qualifier for world championships and Olympic competitions.

This article investigates the Pan Am Games in Toronto: assessing the perspectives of local authorities, Games organizers, and members of the sports community, on the expected sporting legacies of the Games. Specifically, this article examines the understandings of the term and applications of the concept of "event legacy” among Pan Am Games organizers and civic leaders in the region. Further, it investigates what these individuals expect to be the sport legacies of the Pan Am Games in the city of Toronto. Finally, it questions which barriers exist that may hinder progress towards fulfilling the expected sport legacies.

\section{Literature Review}

Event legacies are a relatively new area of inquiry that emerged as a research topic in the mid-1980s (Burns, Hatch, \& Mules, 1986; Hall, 1992; Richie, 1984). Following the early legacy research of the 1980s, there have been a number of publications on legacies across the fields of business (Burns et al., 1986; Curi et al., 2011; Oliver, 2013), tourism (Li \& McCabe, 2012; Stevenson, 2012; Yu \& Turco, 2003), sports (Cornelissen, Bob, \& Swart, 2011; Dickson, Benson, \& Blackman, 2011; Hall, 1992; Weed et al., 2012), and mega-events (Minnaert, 2012; Richie, 1984; Thomson et al., 2013; among others) that focus on the long-term outcomes of events, namely: legacies. And yet, despite growing interest and attention, event legacy remains an illdefined term and concept.

Essex and Chalkley (1998) defined legacy as a "matter of debate and controversy” (p. 95). The most frequently referenced definition of event legacy in the literature is Preuss (2007): "irrespective of the time of production and space, legacy is all planned and unplanned, positive and negative, tangible and intangible structures created for and by a sport event that remain longer than the event itself” (p. 308). This definition incorporates the multifaceted (Chalip, 2006) and multidimensional (de Moragas, Kennett, \& Puig, 2000) nature of the concept. Indeed, this definition suggests a matrix for understanding event legacies, in which each of the proposed elementsplanning, positivity, tangibility - can exist on a spectrum, which complicates the concept and the measurement of legacy.

Event organizers, community leaders, and public officials frequently cite legacies as justification for bidding on and hosting mega-events and to justify the need for the large public expenditures that accompany them (de Nooij, 2012; Hall, 2006; Kasimati, 2003; Thomson et al., 2013). Public officials use events as an opportunity to gain international media attention, grow the local industries, increase tourism, and promote a positive image of a city or country (de Nooij, 2012; Emery, 2002). However, researchers have found there is little empirical evidence to support this justification as most arguments in favor of using mega-events as a driver of economic growth and social reform rely largely on 
anecdotal evidence of past events (King, Leonard, \& Kusz, 2007). Moreover, Cashman (2006) highlighted that "when the term is used by organizing committees, it is assumed to be entirely positive, there being no such thing as negative legacy” (p. 15). It is usually believed that legacy benefits flow to a community at the end of the Games as a matter of course (Cashman, 2006). These are the two key pitfalls to the legacies argument: 1 ) the expectations are unfounded, and 2) legacies are often viewed in a solely positive light, rather than acknowledged as a phenomenon with potential negative legacies. We have already witnessed negative legacies of events. For example, there was a breakdown of historic communities because of the new builds for the 2007 Pan Am Games in Rio (Curi et al., 2011), and cost overruns that negatively impact the host city's public accounts, like the case of the Montreal 1976 Olympics (Whitson, 2004).

Preuss (2007) identified five types of legacies: sporting, urban, infrastructural, economic, and social. Minnaert (2012) expanded on this by suggesting that these can relate to 1 ) the individual, for example through the development of social capital or health benefits, 2) the community, with improved transport or communication links, better or more regular sport and social programming, and new facilities, or 3 ) the image, status, and sense of place of the residents of the host city/country (through the establishment or support of nationalism, feel-good factor, civic pride, positive city reputation, etc.)

Determining a way in which to measure legacies is complicated by time scale, scope, and relevancy of the various impacts, effects, and outcomes of an event, and remains a topic of debate among academics (Cornelissen et al., 2011; Dickson et al., 2011; Gold \& Gold, 2009; Li \& McCabe, 2012; Stevenson, 2012). One manner of measurement, from an economic perspective, is to compare the changes in the economic indicators of the host city as a result of the event (the "event case"), with the economic indicators in the absence of the event (the "without case") (Thomson et al., 2013). On the social level, there are several indicators that can be tracked to evaluate social legacies: "awareness levels of the host nation/city, destination image level changes, social benefits and social costs" (Li \& McCabe, 2012, p. 399), to name a few. Beyond the questions of what timeline and scope to use when measuring legacies, it is important to determine which stakeholders to consult, as "destinations are notoriously difficult entities to manage due to the multiple stakeholder scenarios that underpin their development, management and marketing” (Fyall \& Shipway, 2012, p. 5).

Despite the controversy in defining and measuring legacies, the use of an "event strategy" has been suggested to serve as a starting point for building and measuring legacies as "some legacies of mega events are similar ... [and] synergistic effects are possible when a legacy of one event is a prerequisite for another event” (Preuss, 2007, p. 214). This is especially relevant in cases like Toronto, where there was a multisport event just 3 years ago: the Ontario Summer Games, and other soft infrastructure that was built for past Olympic bids.

The type of legacy that receives the most hype in the literature, and the focus of this article, is sport legacies. This body of literature is presented in brief in the next section.

\section{Sport Legacies}

Sport participation legacies are "oft-cited but rarely explored” (Reis, Rodrigues, De Sousa-Mast, \& Gurgel, 2013, p. 437). The Olympic Movement cites sporting legacies as one of the key objectives it seeks to pursue in its project to "contribute to building a peaceful and better world by educating youth through sport” (Olympic Charter, 2014, p. 16) and these are now featured as a central focus of bid documents for Olympic and regional multisport events (Minnaert, 2012). As Preuss (2007) conceptualized, sport legacies can be tangible or intangible, planned or unplanned, positive or negative (Preuss, 2007).

Tangible, or "hard" legacies in the vein of sporting legacies, are the measurable impacts and outcomes of an event: these include the building or updating of new facilities, the economic boost to the sport and sport-related industries, and new sport infrastructure that remains in place after the event (Preuss, 2007). However, it is important to note that not all hard legacies are positive (Cashman, 2006; Preuss, 2007).

For example, in the case of Olympic and Paralympic infrastructure, misuse or underutilization 
post-Games can lead to these becoming "white elephants" (Weed et al., 2012): difficult to maintain, expensive, and a sore memory of a missed opportunity. An example of this is the 2004 Athens Olympics (Kissoudi, 2010) where infrastructure was built and went unused after the event. However, sporting infrastructure that is built for an event can have positive legacies, and often serve as symbols of the city once the event concludes (Chappelet \& Junod, 2006). For example, the buildings and infrastructure erected for Barcelona 1992 played a role in revitalizing the city's sporting scene, fan culture, and tourism industry (Valera \& Guardia, 2002).

Events also have the capacity to play a large role in affecting change through the "soft" legacies of the event such as increased availability of facilities, an increased variety of sport activities for the local community (Cornelissen et al., 2011), fan support, organizational structure, awareness of the event and of sport more generally, civic pride, and sport participation (Minnaert, 2012).

Increases to sport participation in the host city or country are one possible sport legacy of a megaevent (Chalip, 2006; Girginov \& Hills, 2008; Weed et al., 2012). Sport participation has proven benefits for individual and community benefits such as improved health, contributions to neighborhood activities, development of social capital, and improved attitudes towards young people (Bailey, 2005). Further, studies (Gratton \& Henry, 2001; Henry, 2005) have shown that sport participation can lead to greater community pride, better employment prospects, and intercultural understanding. The Olympic Charter stresses sport participation by stating that "the practice of sport is a human right” (Kissoudi, 2010, p. 11). And yet, efforts to produce a sport participation legacy have been inconsistent, showing varying degrees of success. For example, research conducted on the Sydney 2000 Olympics (Bauman, Ford, \& Armstrong, 2001; Veal, Toohey, \& Frawley, 2012) found that the Olympics had a negligible sport participation legacy, with no noticeable change to the overall physical activity levels during and after the Games. However, the Australian Sports Commission (2001) noted that the Sydney Olympics did result in significant increases in participation in other areas, such as sport spectatorship and television viewing. The most significant increases in sport participation as a legacy of sport mega-events can be seen among existing athletes who become more involved in their sport, or take up new sports (Vigor, Mean, \& Tims, 2004). Most recently, the London 2012 Olympics (Weed et al., 2012) had a similar fate to Sydney: high hopes and few legacies. Changes to the rate of physically active populations in the UK were negligible, despite the goal of higher sport participation nationwide (Donnelly \& Kidd, 2008).

The literature cites two ways to inspire the population to become involved in sport and to increase participation rates: first, through the "demonstration effect” (Li \& McCabe, 2012) that is aimed at individuals who are already physically active, and inspires them to try new sports or to practice their sport more; and second, through the "festival effect" (Li \& McCabe, 2012), which is aimed at individuals who are not physically active by "de-emphasiz[ing] the sporting element of the Games and promot[ing] the festival element” (Weed et al., 2012, p. 75). The festival element is the cultural programming, ceremonies, and non-sport-related programming that runs in conjunction with the mega-event (Weed et al., 2012). These approaches suggest that by hosting a mega-sporting event, the population will naturally be inspired to become involved in physical activity, either through the demonstration effect or the festival effect. However, it has been suggested that to achieve any participation legacy, the event organizers have to put legacy plans in place with long-term execution strategies, otherwise they will not see results: "just as it is naive to assume that participation will increase automatically if Canadian athletes win gold medals, it would be naive to adopt an 'if you build it, they will come' strategy” (Donnelly \& Kidd, 2008, p. 7). For changes to be affected and for legacies to be realized, "it is crucial for legacies to be built into the whole programme for hosting a sporting mega-event” (Kearney, 2005, p. 390).

\section{Gaps and Inconsistencies in the Literature}

Mair and Whitford (2013) identified event outcomes and legacies as a priority area of research for the events field, and yet despite the increase in research in this area (Reis et al., 2013), there remain significant gaps in the literature.

The literature is inconclusive on accepting a definition for "legacy," and for determining how best to 
measure legacies, although solving the former may inform the latter. There is also a lack of research on how legacies affect different segments of the population (e.g., children, the poor, the disabled, the elderly, and the LGBTQI community). Barriers to realizing legacies are also underresearched. So too are strategies for the implementation of legacies. The Pan Am Games offer a unique opportunity to explore some of these questions further, as Toronto has never before hosted an international multisport event nor a mega-event, therefore the city benefits from a particularly clean platform from which to observe changes, reactions, responses, and short- or long-term legacies to the Pan Am Games. Further, the city has demonstrated an interest in creating legacies, as evidenced through their multiple bids in the past that highlighted legacies, as well as Section 18 of the Pan Am 2015 bid that outlines the key legacy goals (TO2015 Bid Committee, 2009) and the Playing for Keeps Initiative that focuses specifically on sport legacies (Misener, 2013).

Not all academics accept the use of the terms and concept of "event legacy." Cashman (2006), for instance, suggested that perhaps the term is too loosely defined, and taken for granted as a "point of convergence for the thinking of groups with widelydivergent views and agendas" (Gold \& Gold, 2009, p. 15). Gold and Gold (2009) went further to suggest that legacies are "little more than a convenient omnium gatherum for diverse phenomena” (p. 15). From this skeptical perspective, events could be said to fall into the framework of philosopher Debord's (1977) "spectacle," which posited that the "tautological character of the spectacle flows from the simple fact that its means are simultaneously its ends" (p. 13). In this theoretical framework, the "spectacle" is the event, which would have no further purpose or responsibility to the people or its environment beyond the event itself.

The Pan Am Games have attracted little interest from academics (Curi et al., 2011; Feldman, Zhu, Simatovic, \& To, 2014; Klie, 2011; Whitford, 2015). The literature that exists on Pan Am does not focus on sport or sport legacies.

The gaps in the literature, namely the inconclusive definition of "event legacy," the sporting legacies of games other than Olympics, the barriers to legacy fulfilment, and the lack of research on Pan Am Games from a sport perspective are addressed in this article. The gaps in the research informed a set of research questions that were used to guide the interviews.

These were:

RQ1: Are members of the sport community familiar with the concept of event legacies?

RQ2: How do they define "event legacy?"

RQ3: What do the respondents expect will be the legacies of the Toronto 2015 Games?

RQ4: What barriers affect the realization of the sport legacies?

The methodology and findings of this research are detailed in the following sections.

\section{Methodology}

This research was conducted using semistructured interviews with a sample of respondents, purposefully sampled from a pool of stakeholders. Interviewing is a recognized method of gathering information on respondents' attitudes and perspectives (Rowley, 2012), and was selected as the appropriate method for this study because many of the research subjects who were approached hold positions of employment and affiliation with various stakeholder groups in the event and may not feel comfortable speaking openly about their opinions and perspectives in a group setting.

Respondents were identified by the researcher, or referred by the Toronto Sports Council, with the view of recruiting a diverse sample, as this is crucial to offering a holistic view of the various viewpoints on the research questions (Fyall \& Shipway, 2012; Rowley, 2012). Participants were sent a preinterview e-mail that offered some information about the researcher and the research question, as well as a statement about confidentiality and consent. All participants verbally agreed to participate at the beginning of their interview, and agreed to the interview being recorded, and to the data being used for academic research purposes, and possibly publication. The research subjects were predominantly residents of Toronto from a variety of backgrounds, with varying degrees of involvement in the event, interests, and affiliations. The researcher took care to ensure an even number of male and female respondents, varying in age between 18 and 
71 years old, with different socioeconomic backgrounds (see Table 1).

Once granted the ethical approval of the University, the researcher conducted a literature review to identify the empirical gaps in the research. A preliminary set of five standard questions was set by the researcher, which were used in each interview and elaborated or edited to follow the prompts of interview participants to draw data specific to sport legacies, definition of legacy, and barriers to the legacies.

Each interview recording was transcribed verbatim. Each transcript underwent two rounds of content analysis, one manual, one using NVivo (Leech \& Onwuegbuzie, 2011) to identify the salient points and themes. The transcripts were then inductively coded (Fereday \& Muir-Cochrane, 2006), and analyzed for response frequency, similarities, and differences across the lot. The results and implications of this analysis are discussed in the following sections.

\section{Results}

\section{Defining Legacy}

The first two questions of each interview asked the respondent whether they were familiar with the concept of event legacy, and to define it. The degree of familiarity varied, as did the definitions that were offered.

The most common response, offered by a number of stakeholders, was "what gets left behind" or "what we are left with." According to a few of them, legacies are "changes" and "mindshifts" that are the result of an event that takes place. A third common response was that events can serve as catalysts for other opportunities or infrastructure, and that those opportunities or infrastructure that are created are the legacies. This third response has certain similarities to the first two responses, in that the new opportunities and infrastructure are changes to what used to be, and could be framed as something that is "left behind."

The fourth response that was offered is more elaborate and touches on both "hard" and "soft" legacies. Respondent 12 clearly identified legacies as being one of two things: physical capital or social capital that is created, developed, or strengthened as a consequence of the event. Respondent 9 elaborated on the definition slightly differently, offering a list of possible legacies from events:

There are a few lenses to look at this, but I'll name a few. There's the infrastructure and the

Table 1

List of Interview Respondents

\begin{tabular}{l} 
Type of Stakeholder/Identifier and Affiliations of Interview Participants \\
\hline Sport groups \& advocacy bodies \\
Respondent 1, Toronto Sports Council \\
Respondent 2, Ontario University Athletics \\
Pan Am and Parapan Am volunteers \\
Respondent 3, Toronto Sailing Club \\
Event organizers \\
Respondent 4, TO2015 Bid Committee and TO2015 Organizing Committee \\
Respondent 5, City of Toronto (Pan Am Office) \\
Respondent 6, City of Toronto Department of Parks, Forestry and Recreation \\
Civic leaders \\
Respondent 7, City Councillor, Ward 33 \\
Respondent 8, Member of Parliament for Canadian Federal Government \\
Respondent 9, Ministry of Tourism, Sport and Culture (Province of Ontario) \\
Pan Am and Para Pan Am athletes \\
Respondent 10, Women's Water Polo \\
Organizations with relationships to the Games \\
Respondent 11, Toronto Foundation and TO2015 Ignite Program \\
Respondent 12, OutSport Toronto \\
Respondent 13, Mississaugas of the New Credit First Nation \\
Physical education professional in Toronto \\
Respondent 14, Toronto Catholic District School Board
\end{tabular}


on-going investments there. The sport participation may increase through people watching and being inspired, and having new facilities to go to. There's social capital building that happens . . . and then there's the transport legacies ... . and then on the softer side, legacies can relate to the host city's view or perception of being a global city, or being a sport city. Just building awareness around the city and what's available and what's going on.

Either directly in their definition of legacy, or in the discussions that followed later in the interviews, each of the respondents mentioned at least one legacy that is considered "hard" and at least one legacy that is considered "soft." Although not all of the respondents were aware of the difference between the two, especially those less familiar with the concept of legacy, the two types of legacy did come out in each interview.

As for the temporal element of legacies, more than half of the respondents did not mention this at all. There were six respondents who did offer a temporal element to their definition of their discussion of legacies, all of whom specifically mentioned the long term, and one also used the word "permanent." Not one respondent mentioned the short term.

Four of the respondents considered the legacies to be automatic. Thirteen of the respondents only considered positive legacies. The only individual who considered that legacies could be negative or less desirable was Respondent 2, who had no direct involvement in the Games. These findings are congruent with Cashman's statement that organizers and public officials often speak of legacies solely in a positive light (Cashman, 2006), perhaps to garner support for the event and the expenditures that accompany the event.

The answers to the questions about defining "legacies" were inconsistent, which suggests that this study was no more successful in finding a definition of legacy than the literature, and lends credibility to Gold and Gold's (2009) conclusion that legacies are a miscellaneous collection of different things, beliefs, processes, changes, and understandings.

\section{Sport Legacies of Toronto 2015}

The most frequently cited legacy, by 11 of the 13 respondents, was new or improved sport facilities and equipment. Some respondents named specific new buildings, sports grounds, or upgrades to existing facilities. For example, Respondent 10 highlighted the new water polo facility in Markham:

There are so many new facilities and new services for athletes . . . and all of these facilities were purpose-built, so for a sport like water polo, we need a certain sized pool, and polo nets, and room in the stands. ... . And I'm guessing the cyclists are thinking the same with their new Velodrome, it's nice having things set up in just the way you need them to train.

Respondent 10's sport-specific approach highlights the elite-level nature of the new facilities that were built, and how beneficial these will be to the elite athletes' training moving forward.

Respondent 5 offered the most comprehensive list of new builds and sport infrastructure, highlighting the planned and expected nature of these legacies:

The Pan Am Games Capital Program . . . consists of 10 projects, the two biggest of which involved the development of a new aquatic centre and field house at $\mathrm{U}$ of $\mathrm{T}$ Scarborough Campus . . . there are also three existing tracks that are being upgraded . . . there's a new BMX cross course being built out in Centennial Park, and there's an upgrade to what's called the Left Channel . . . up to $20 \mathrm{~km}$ of roads that are being resurfaced for the cycling road race, and there's the Pan Am Path as well, which is $80 \mathrm{~km}$ of cycling paths in the City.

Other respondents, for example Respondent 4, were more general in their discussion of the city of Toronto and the new sport infrastructure as legacies:

You know, Toronto wanted to develop parts of its city, and we wanted to do that with the 2008 Olympics. Now we get to do that with Pan Am. We're going to have new facilities and new places for athletes to train, and the younger kids will see them training and play there, too.

All the respondents who named sport infrastructure as a legacy of the Games spoke of them in a positive light. Sport infrastructure legacies are easily measurable and could be easily reviewed over the short or long term to see whether they continue to be used and whether they impact sport participation or improve access to facilities. 
The second most named legacy was increased awareness of sport and sport opportunities in the city. This was viewed as a positive legacy. The increase in awareness was linked to different phenomena; for example, Respondent 10 highlighted the heightened awareness among the athletes and the coaching community, while Respondent 8 credited social media with an expected increase in awareness of Canadian athletes and their accomplishments:

I think that with social media, there's a legacy of awareness of all these amazing athletes who live amongst us invisibly, because they're working so hard participating around the world and we don't even see them as neighbours.

Others referred more specifically to awareness of amateur sports and the different sports that are played in the Pan Am Calendar, comparing them to the more publicized and commercialized professional sports teams in Toronto:

We've been a hockey town historically, and I think what you'll start to see if some of that changing a bit. A deeper appreciation for amateur sport, and a deeper appreciation for the range of sports that people now like to play and that are a part of the Olympic calendar or sport and the Pan Am calendar. (Respondent 5)

There were three respondents that highlighted two specific groups of people and a heightened awareness of their sporting accomplishments: the para-athletes, mentioned by Respondent 6 , and the female athletes, mentioned by Respondents 2 and 14. Finally, Respondent 1 suggested that the scope of the awareness legacy may stretch wider than the Toronto area itself: "People will see this, and hear about it, and the awareness will be wider spread than the Golden Horseshoe and the 18 communities around it, but also, certainly, anyone who is touched by the Torch Relay.”

Seven respondents thought that inspiration factor would be a positive legacy of the Pan Am Games, and some even suggested that this would lead to increased sport participation:

I think that all the athletes, coaches and staff or volunteers were inspired to be there, and to see what we can accomplish. I was also shocked by the number of people who attended the races and ceremonies, it was a lot more than I had expected, so they were clearly driven to attend and get involved as spectators. Hopefully some of those feelings of inspiration will last. (Respondent 3)

The expected awareness and inspiration legacies are intangible, requiring further interviews and qualitative research in the future. According to the literature, the most likely people to be inspired by a multisport event to become more involved in sport or to try a new sport are those who already lead physically active lifestyles (Li \& McCabe, 2012). This could be reviewed in a follow-up study on the inspiration legacies of Toronto 2015 as well.

Two respondents mention new funding streams as an expected legacy, while three others named funding legacies in conjunction with another legacy, for example maintenance or development funds for the new infrastructure. According to Respondent 12 , "there is a legacy fund to supplement the cost of maintaining these facilities, and that fund will be there for the next 20 years.” This suggests not only a funding legacy as a positive legacy, but as a longterm legacy. It is noteworthy that although only one respondent named financial legacies as part of their definition of legacy, it came up in the question about "what will the legacies be" more often, and finances were frequently brought up as a concern in discussions about barriers to legacy fulfilment.

A number of other legacies were named, including new partnerships among sport groups and organizing bodies, hosting experience, increased social capital, physical literacy, and sport participation. However, none of these were elaborated upon, nor were they the primary focus in any of the respondents' discussions on the expected legacies of these Games.

There were four types of sport legacies that were notably absent from the interview results: personal legacies, international sport legacies, parasport legacies, and negative legacies. Not one respondent offered insight into any of these, unless they were prompted by the researcher to discuss them specifically. This may be because of a limited understanding of legacies, or perhaps the questions on the legacies of the event were not specific enough in asking about the scope of legacies.

\section{Barriers}

Bureaucracy, high costs, inaccessibility, and disinterest were the most cited barriers to the fulfilment 
of the sport legacies named by the respondents. Other possible barriers were cultural barriers, and lack of space for new facilities and infrastructure. Four respondents did not offer any barriers at all.

To help respondents understand the question on barriers, the researcher asked some respondents to elaborate upon the question, by asking about specific populations, and whether the benefits and legacies would affect everyone equally. Each person that was asked about this agreed that the legacies would be felt unequally across Toronto, either due to geographical or socioeconomical differences. However, each individual identified a different segment of the population in their discussion of who they felt would benefit more or less from the legacies. For example, Respondent 13 highlighted the cultural limitation of a regional Games: "Pan Am concentrates on a certain sector of people, it's more Latin American and South American, so can be seen as automatically exclusionary to other cultures," and Respondent 11 suggested that location and placement of the venues may make it harder for some people to access and benefit from than others: “If you don't have a car and you live downtown, it's going to take you a while to get to the BMX facility or the Aquatics Centre.” Respondent 1 cited high participation costs as an explanation for poorer communities being unable to benefit from the sport infrastructure legacies: "A lot of people in Toronto, especially newcomers, are struggling to feed their families. Their priority is not sport, it's survival. So, there's a financial barrier there.” Ultimately it proved to be easier to discuss barriers when they were framed in the context of some people benefiting more than others. Perhaps the barriers are more community specific than general. More research is needed in this area in the future to investigate whether the expected legacies of these games did materialize, and to what extent the expected barriers hindered their progress, if at all.

\section{Discussion}

This research study was limited to researching only the expected sport legacies. Further, it was limited to a small number of respondents as the one-on-one nature of interviews offer fewer respondents than focus groups or questionnaire methods (Rowley, 2012). Another limitation of this study, that is common in legacy research, is the lack of research into the perspectives of the public. Although most the respondents of this investigation are also residents of Toronto, they all have some degree of interest or involvement in the event. Future research could focus the perspectives of uninvolved parties to gain a more holistic understanding of opinions on the topic.

The findings of the study show that although most respondents were aware of the term "legacy" and had some knowledge of the concept, few had a holistic understanding of what was involved in a legacy, omitting either the temporal element, the negative element, the hard or soft legacies, or negative legacies. It is noteworthy that even the respondents with high degrees of involvement in the Games did not have consistent answers to the question about defining legacies. For the question on expected sport legacies, the answers were, again, inconsistent. However, the three most mentioned legacies were: 1) new or improved sport infrastructure, 2) increased awareness of sport or sport opportunities, and 3) inspiration. The first is salient as it is the first legacy named in the Toronto 2015 bid:

The Games will create much needed new and updated sport facilities in Canada's most populous region. These facilities will be key community legacies that will launch athlete development through grassroots sport and increased physical activity within the general population. (TO2015 Bid Committee, 2009, p.199)

With the majority of respondents highlighting this expected legacy, which is arguably the most easily measured, it will be interesting to see whether the efforts invested in this legacy plan, of which many people are aware, will be fruitful. This will require a follow-up study in a few years, for a long-term review, perhaps with some of the same respondents of this study to revisit their answers and perspectives.

The questions relating to barriers yielded the most difficult data to analyze, as the results were inclusive, with many respondents requiring clarification to offer an answer. One possible explanation for why the recipients were so challenged by the question is that the lenses through which the respondents are viewing the expected legacies were limited to positive legacies. Therefore, the respondents may have 
found it difficult to conceptualize of negative legacies and barriers. An alternate explanation would be that the respondents, many of whom are directly involved in the production of Pan Am in some way, are supportive of the legacy rhetoric of the Games for political reasons. This highlighted an important point about legacies: the literature has suggested (Cashman, 2006), and the response to this question supports, that legacies are often viewed solely only in a positive light. This finding supports Debord's (1977) theory of the spectacle: that the event has no purpose beyond the spectacle itself, but to entertain and be enjoyed.

The question on barriers also revealed an unexpected finding in this study, which is that not all segments of the population will benefit equally from the positive legacies that may come of the Games. A follow-up study, as suggested for further review of the sport infrastructure legacies, could inform this point further by investigating how the different populations of Toronto benefitted-or did not benefit-from the sport legacies of the Toronto 2015 Games, and what factors inhibited their benefiting, where relevant.

\section{Conclusion}

The findings of this examination of Toronto's Pan Am legacies have found consistency with the literature, and two major themes that have emerged. First, that there is no universal understanding of legacies as a term or concept, and second, that the results of planned legacy efforts have been inconsistent in terms of being positive or negative for the host city.

Perhaps a universal definition of legacy is inappropriate. Given the disparities between events (Gold \& Gold, 2009; King et al., 2007; Li \& McCabe, 2012), it would be more appropriate to determine a definition of legacy on an event-by-event basis in specific language. In coming to an agreement on a comprehensive definition of legacy with all stakeholders involved in a given event (or as many stakeholders as possible), it would be easier for organizing committees and host communities to set strategic and specific target-based goals, directed towards producing achievable legacies. With both a clear and comprehensive definition and a set of targeted goals, it would be easier to measure and evaluate the legacies of that event. Should this lead to desirable results in legacy development; then organizers would have a founded argument for investing in mega-events as a means of benefitting their city.

\section{Acknowledgment}

This research was conducted in partial fulfillment of the first author's candidacy for the Masters of Science in International Events Management degree at the University of Brighton (awarded in 2015). The authors would like to thank the academic faculty members at the School of Sport and Service Management for their support in this project.

\section{References}

Bailey, R. (2005). Evaluating the relationship between physical education, sport and social inclusion. Educational Review, 57(1), 71-90.

Bauman, A., Ford, I., \& Armstrong, T. (2001). Trends in population levels of reported physical activity in Australia, 1997, 1999 and 2000 (Rep.). Canberra, Australia: Australian Sports Commission.

Burns, P., Hatch, J. H., \& Mules, T. J. (1986). The Adelaide Grand Prix: The impact of a special event. Adelaide, Australia: Centre for South Australian Economic Studies.

Cashman, R. I. (2006). The bitter-sweet awakening: The legacy of the Sydney 2000 Olympic Games. Petersham, NSW: Walla Walla Press in conjunction with the Australian Centre for Olympic Studies, University of Technology, Sydney.

Chalip, L. (2006). Towards social leverage of sport events. Journal of Sport \& Tourism, 11(2), 109-127.

Chappelet, J., \& Junod, T. (2006). A tale of 3 Olympic Cities: What can Turin learn from the Olympic legacy of other Alpine cities? In Valencia Summit, Lausanne, Swiss Graduate School of Public Administration, 83-89.

Cornelissen, S., Bob, U., \& Swart, K. (2011). Towards redefining the concept of legacy in relation to sport mega-events: Insights from the 2010 FIFA World Cup. Development Southern Africa, 28(3), 307-318.

Curi, M., Knijnik, J., \& Mascarenhas, G. (2011). The Pan American Games in Rio de Janeiro 2007: Consequences of a sport mega-event on a BRIC country. International Review for the Sociology of Sport, 46(2), 140-156.

De Moragas, M., Kennett, C., \& Puig, N. (2003). The legacy of the Olympic Games, 1984-2000: International Symposium, Lausanne, 14th, 15th and 16th November 2002. Lausanne, Switzerland: International Olympic Committee.

De Nooij, M. (2012). Mega sport events: A probabilistic social cost-benefit analysis of bidding for the games. Journal of Sports Economics, 15(4), 410-419. 
Debord, G. (1977). Society of the spectacle. Detroit, MI: Black and Red.

Dickson, T. J., Benson, A. M., \& Blackman, D. A. (2011). Developing a framework for evaluating Olympic and Paralympic legacies. Journal of Sport \& Tourism, 16(4), 285-302.

Donnelly, J., \& Kidd, B. (2008). Opportunity knocks! Increasing sport participation in Canada as a result of success at the 2010 Vancouver Olympics. Toronto: Centre for Sport Policy Studies, University of Toronto.

Emery, P. (2002). Bidding to host a major sports event. International Journal of Public Sector Management, 15(4), 316-335.

Essex, S., \& Chalkley, B. (1998). Olympic Games: Catalyst of urban change. Leisure Studies, 17(3), 187-206.

Feldman, L., Zhu, J., Simatovic, J., \& To, T. (2014). Estimating the impact of temperature and air pollution on cardiopulmonary and diabetic health during the TORONTO 2015 Pan Am/Parapan Am Games. Allergy, Asthma \& Clinical Immunology Allergy Asthma Clin Immunol, 10(Suppl 1), A62.

Fereday, J., \& Muir-Cochrane, E (2006). Demonstrating rigor using thematic analysis: A hybrid approach of inductive and deductive coding and theme development. International Journal of Qualitative Methods, 5, 80-92.

Fyall, A., \& Shipway, R. (2012). International sports events: Impacts, experience and identities. London, UK: Routledge.

Girginov, V., \& Hills, L. (2008). A sustainable sports legacy: Creating a link between the London Olympics and sports participation. The International Journal of the History of Sport, 25(14), 2091-2116.

Gold, J., \& Gold, M. (2009). Riding the Mexican wave? Deciphering the meaning of Olympic Legacy. In J. Kennell, C. Bladen, \& E. Booth, (Eds.), The Olympic legacy: People, place, enterprise (1st ed.) (pp. 9-20). London, UK: University of Greenwich.

Gratton, C., \& Henry, I. P. (2001). Sport in the city: Where do we go from here? In C. Gratton \& I. P. Henry (Eds.), Sport and the city: The role of sport economic and social regeneration (1st ed.) (pp. 309-314). New York, NY: Routledge.

Hall, C. M. (1992). Hallmark tourist events: Impacts, management, and planning. London, UK: Belhaven.

Hall, C. M. (2006). Urban entrepreneurship, corporate interests and sports mega-events: The thin policies of competitiveness within the hard outcomes of neoliberalism. In J. Horne \& W. Manzenreiter (Eds.), Sports megaevents: Social scientific analyses of a global phenomenon (1st ed.) (pp. 59-70). Oxford, UK: Blackwell.

Henry, I. (2005). Sport and multiculturalism: A European perspective (1st ed.). Barcelona, Spain: Centre d'Estudis Olympis UAB.

Kasimati, E. (2003). Economic aspects and the Summer Olympics: A review of related research. International Journal of Tourism Research, 5(6), 433-444.
Kearney, A. (2005). Building a legacy: Sports mega-events should last a lifetime. Retrieved from http://www.kzndsr. gov.za/Portals/0/GIS/BuildingaLegacy[1].pdf

King, C., Leonard, D., \& Kusz, K. (2007). White power and sport. Journal of Sport and Social Issues, 31(1), 1-9.

Kissoudi, P. (2010). Athens' Post-Olympic aspirations and the extent of their realization. The International Journal of the History of Sport, 27(16-18), 2780-2797.

Klie, S. (2011). Pan Am Games a massive HR undertaking. Canadian HR Reporter 24(3), 1-2.

Leech, N. L., \& Onwuegbuzie, A. J. (2011). Beyond constant comparison qualitative data analysis: Using NVivo. School of Psychology Quarterly, 26(1), 70-84.

Li, S., \& McCabe, S. (2012). Measuring the socio-economic legacies of mega-events: Concepts, propositions and indicators. International Journal of Tourism Research, 15(4), 388-402.

Mair, J., \& Whitford, M. (2013). An exploration of events research: Event topics, themes and emerging trends. International Journal of Event and Festival Management, 4(1), 6-30.

Minnaert, L. (2012). An Olympic legacy for all? The noninfrastructural outcomes of the Olympic Games for socially excluded groups (Atlanta 1996-Beijing 2008). Tourism Management, 33(2), 361-370.

Misener, L. (2013). Events and social capital. In R. Finkel, D. McGillivray, G. McPherson, \& P. Robinson (Eds.), Research themes for events (1st ed.) (pp. 18-30). Wallingford, UK: CABI.

Oliver, R. (2013). The legacies of losing: Rethinking the "failure" of Toronto's Olympic Games bids. Sport in Society, 17(2), 204-217.

Olympic Charter. (2014). Olympic charter. In force as from 2 August 2015. Lausanne, Switzerland: International Olympic Committee. Retrieved from http://www.olympic.org/Documents/olympic_charter_en.pdf

Preuss, H. (2007). The conceptualisation and measurement of mega sport event legacies. Journal of Sport \& Tourism, 12(3-4), 207-228.

Reis, A. C., Rodrigues, F., De Sousa-Mast, \& Gurgel, L.G. (2013). Rio 2016 and the Sport participation legacies. Leisure Studies, 33(5), 437-453.

Ritchie, B. (1984). Assessing the impact of Hallmark events: Conceptual and research issues. Journal of Travel Research, 23(1), 2-11.

Rowley, J. (2012). Conducting research interviews. Management Research Review, 35(3/4), 260-271.

Stevenson, N. (2012). Culture and the 2012 Games: Creating a tourism legacy? Journal of Tourism and Cultural Change, 10(2), 137-149.

Australian Sports Commission. (2001). The sporting legacy of the 2000 Sydney Olympic Games. Canberra, Australia: Sport Development Unit.

Thomson, A., Schlenker, K., \& Schulenkorf, N. (2013). Conceptualizing sport event legacy. Event Management, 17(2), 111-122. 
TO2015 Bid Committee. (2009). Toronto 2015: Your moment is here. The final Bid Book submitted to PASO to advance the candidacy of Toronto for the hosting rights of the 2015 Pan Am Games.

Valera, S., \& Guardia, J. (2002). Urban social identity and sustainability: Barcelona's Olympic Village. Environment and Behavior, 34(1), 54-66.

Veal, A. J., Toohey, K., \& Frawley, S. (2012). The sport participation legacy of the Sydney 2000 Olympic Games and other international sporting events hosted in Australia. Journal of Policy Research in Tourism, Leisure and Events 4(2), 155-184.

Vigor, A., Mean, M., \& Tims, C. (2004). After the goldrush: A sustainable Olympics for London. London, UK: Institute for Public Policy Research.
Weed, M., Coren, E., Fiore, J., Wellard, I., Mansfield, L., Chatziefstathiou, D., \& Dowse, S. (2012). Developing a physical activity legacy from the London 2012 Olympic and Paralympic Games: A policy-led systematic review. Perspectives in Public Health, 132(2), 75-80.

Whitford, S. (2015). San Antonio, Miami, Raleigh Vie for 2007 Pan Am Games. Dallas Business Journal, 22(3), 14.

Whitson, D. (2004). Bringing the world to Canada: “The periphery of the centre.” Third World Quarterly, 25(7), 1215-1232.

Yu, Y., \& Turco, D. M. (2003). Issues in tourism event economic impact studies: The case of the Albuquerque International Balloon Fiesta. Current Issues in Tourism, 3(2), 138-149. 